The anæsthetics up to quite recent years were invariably given by the dressers in the eye wards, none of whom had much previous experience ; indeed, many of them gave an anæsthetic for the first time under my supervision. Out of the whole number there was but one death, that of a patient suffering from exophthalmic goitre. The anæsthetics chiefly used were in the early years bichloride of methylene and chloroform, but occasionally a new one was given a trial. Later A.C.E. mixture became the mainstay in the eye wards and continued to be up to the end of my time. $\mathrm{My}$ ex perience seems to show that deaths from anæsthetics per se are extremely rare and that those which, according to the coroners, are so frequent are due to other causes, and the less said about them in this connexion the better, especially if, as Dr. Silk says, the reports get into the lay press. In the interests of the public, who are already quite nervous enough about anæsthesia, the coroners, who can have no practical experience of the administration of anæsthetics, would do well to lay to heart two old proverbs : (1) That the cobbler should stick to his last; (2) That to speak is silver bot silence is gold.-I am, Sir, yours faithfully,

Charles Higgeis, F.R C.S. Eng.

Consulting Ophthalmic Surgeon to Guy's Hospital. Brook-street, W., April 10th, 1908.

To the Editor of THE LANOWT.

SIR,-A letter appeared from Mr. Coroner F. J. Waldo of London in the Dublin Evening Mail of about 14 days ago in which be commented on the very few fatalities from chloroform which were reported from Ireland as compared with London. A somewhat similar state of affairs prevails with regard to Scotland, but Dr. Waldo suggests as an explanation that either Dublin hospital surgeons do not report chloroform fatalities or the Dublin coroner refuses to hold inquests thereon. As this theory implies a grave imputation it is right to say that as a member of the corporation inspection committee of the Dublin hospitals such a complaint has never been made to us regarding any of the surgeons, and such a complaint concerning the coroner has never been made to the Public Health Committee whilst I have been a member of it. It is fairly certain then that Dr. Waldo's conjecture is baseless as regards Dublin.

I am, Sir, yours faithfully,

J. C. McWalrer, M.A. R.U.I., M.D. Brux.,

Dublin, April 25th, $1908 . \quad$ F.F.P. \& S. Glasg.

\section{WORTH'S ADVANCEMENT OPERATION.}

To the Editor of THW LANOET.

SIR,-In a notice of Colonel Maynard's excellent book on "Ophthalmic Operations" in THE LANCET of April 25th, p. 1216, the reviewer expresses the opinion that my advancement operation is "founded upon a fallacy and practical experience shows that it possesses notable disadvantages." Whose "practical experience"? I think that I may claim to have performed more advancement operations than most ophthalmic surgeons and I have used this operation exclusively during the last dozen years. I know from published accounts and private correspondence that this operation is used babitually by many of the most skilful operators both in this country and abroad. Its advantages are many. Its one disadvantage is that the stitches are not quite so easily removed as in some other operations. I do not for a moment suggest that your reviewer was actuated by personal motives when he went out of his way to make this remarkable statement. But I do respectfully suggest that such a statement should not have been made anony. mously or without giving reasons.

I am, Sir, yours faithfully,

Harley-street, W., Lpril 27th, 1908. Claud Wortu.

\section{THE INHALATION TREATMENT OF CONSUMPTION AND "CATARRH." To the Editor of THW LANCET.}

SIR,--I have read with great interest Dr. Ash's remarks that appeared in THE LANCET of April 25th, p. 1236, on the inhalation treatment of consumption. For many years I have advocated the inhalation method as an im. portant aid in the treatment of pulmonary and laryngeal tuberculosis. It is quite true that the inbalation of volatile substances produced by the ordinary respirators, mouth inhalers, and sprays is not satisfactory, as it cannot reach far enough down the lungs to be of any real service in the arrest of consumption. Two conditions are necessary for any inhaler to be efficacious: (1) the inhaler should cover the mouth and nose; and (2) it must be continuously used for as many hours as possible. The anatomical structure of the lungs lends itself peculiarly to antiseptic treatment. For some years I have been using among my patients an oronasal inhaler containing a mixture of formalin, chloroform, and rectified spirit, with a few drops of oil of pine or eucalyptus. The advantage of this method is that the patient can use it walking out of doors or reading, writing, or otherwise employed indoors. The success, as Dr. Ash pointed out, depends upon its continuous use, at least from four to six hours a day. Another good method mentioned by Dr. Ash is that of impregnating a chamber with volatile antiseptic substances. I use the patient's room as an inhalation chamber in preference to a special inhalation room, and have devised a vapouriser in which one or two formalin tablets with a little menthol are volatilised, the room being made more or less air-tight by shutting the doors and windows. The advantage of this method is that for hours the room is charged with formalin vapour, enabling the patient to inhale the impregnated air and rendering his clothes and his belongings in the room aseptic. The patient can use both these methods in a sanatorium or in his own house. My experience is that perseverance often results in success. But the trouble is that patients will not persevere long enough.

Mendip Hills Sanatorium, Wilts.

C. MUTHU

\section{THE ROYAL DENTAL HOSPITAL: A} SPECIAL APPEAL.

To the Editor of THE LANCET.

SIR,- The Royal Dental Hospital has now been established 50 years during which time an incalculable amount of suffering has been relieved and many serious illnesses averted by timely attention to the teeth of the poorer classes.

The committee of management wishes to celebrate the jubilee by making a special appeal to extinguish the debt on the building which so seriously cripples the funds of the charity. This debt was sanctioned by the Charity Commissioners and entailed a yearly payment to the mortgagees of $£ 2,97517 s$. $4 d$. for 30 years from 1902 , of which 24 years are yet unexpired. There now remains $£ 47,4041 s .7 d$. to be paid to wipe off the debt altogether, and it is for contribations, however small, towards this sum for which the committee now appeals. This would mean a saving in the 24 years of about $£ 33,000$ in interest alone, and the money thus set free would be devoted to maintaining the hospital in a much greater state of efficiency than it is at present. It is within the knowledge of everyone that the teeth of the majority of the poorer classes are in a deplorable condition, and that a great number of the children require long and expensive treatment to save them from life-long disfigurement and inconvenience. This they can only obtain at a dental hospital. Over 100,000 operations were performed here last year, half of which were under anæsthetics.

The Royal Dental Hospital should command universal sympathy and support, not only for the benefits it has conferred on its own patients but also because it was the first dental hospital established in Fngland, and from it all skilled dentistry in this country has developed, thus adding to the health, comfort, convenience, and happiness of all classes of the community. About 1200 students have been educated in the hospital and school. After 50 years of hard work it is earnestly hoped that this truly national institution may be freed in this, its jubilee year, from the burden of debt under which it is still struggling.

Sir Frederick Treves, Bart., G.O.V.O., C B., LL.D., consulting surgeon to the hospital, has kindly consented to preside at a festival dinner to be held at the Hotel Cecil on June 25th in aid of the "Special Appeal Fund." Contributions may be sent to the secretary of the hospital.

We have the honour to remain

Your obedient servants

Rothschild, President.

KINNAIRD

F. A. BEVAN (Treasurer)

RICHARD WINCH

JOHN H. HALW, Unairman

Royal Dental Hospital, 32, Leicester-square, London, W.C., April 23rd, 1908. 